\title{
PRINCIPLES FOR EFFECTIVE CLASSROOM DISCOURSE
}

\author{
Dr. Omar Albukbak. \\ Faculty of Arts. \\ Misurata University
}

\begin{abstract}
This article examines the importance of discourse analysis in language classroom. At the outset it describes what the discourse analysis is and its implications. It then proceeds to show the reasons for the learners' difficulties in developing communicative competence and what the teacher should do to get over this problem. This paper also identifies the difficulties the Libyan learners of English face in acquiring English required to communicate in different situations. Then it explains the theory of zone of proximal development and examines the scope of scaffolding which can lead learners to engage in discourse authentically. It also examines the importance of collaborative learning to develop the students' language competence. An example of a classroom activity is also presented. The article ends with the conclusion that discourse analysis in language classroom will greately aid in language teaching and learning.

Key Words: Discourse analysis, scaffolding, zone of proximal development
\end{abstract}

\section{Introduction}

Discourse analysis has now become a rapidly developing discipline in applied linguistics.In language classroom, it focusses on the application of discourse analysis to second language teaching and learning. Even with 
the most communicative approaches, the second language classroom is limited in its ability to develop learners' communicative competence in the target language. This is due to the restricted number of contact hours with the language; minimal opportunities for interacting with proficient speakers and limited exposure to the variety of functions, genres, speech events and discourse types that occur outside the classroom. Given the limited time available for students to practise the target language, teachers should maximize opportunities for student participation.Classroom research is one way for teachers to monitor both the quality and quantity of student' output. The purpose of this article is to throw light on, and highlight the importance of discourse analysis.

\section{The Meaning of Discourse Analysis}

Discourse analysis normally refers to the study of how sentences in spoken and written language form larger units of language such as paragraphs, conversation, interviews...etc, whereas in critical discourse analysis, discourse is used to indicate not only any kind of talk but also the meanings and values embedded in talk (Richard and Schmidt, 2002). Discourse analysis involves looking at both language form and language function. It identifies linguistic features that characterize different genres as well as social and cultural factors that assist in the interpretation and understanding of different types of talk.

According to Richard and Schmidt (2002, p.73-74), classroom discourse is different in form and function from language used in other situations because of the particular social roles students and teachers have in classrooms and the kinds of activities they carry out there. So what is important in classroom discourse is how teachers can improve their teaching practices by investigating actual language use both in and out of 
the classroom, and how students can learn language through exposure to different types of discourse.

\section{Classroom Discourse and Teachers}

In many second language classrooms, it can be hard to develop learners' communicative competence in the target language. One reason could be the limited number of contact hours with the target language and oversized classes. In addition, there may be a small number of opportunities for interacting with native speakers, authentic materials and limited exposure to a variety of speech events and discourse types that resemble real-life situations. As such, teachers should attempt to maximize opportunities for students' participation and try to monitor both the quantity and quality of the input and output. Language teachers should concentrate on their teaching practices, considering the frequency, distribution, and types of questions they use and their effect on students' responses. From my point of view, it is useful to create communication patterns through different classroom activities such as student-student interactions during a role-play task and during a small-group cooperative learning activity. These communicative activities provide opportunities for students to engage in talk and to produce different speech patterns in response to different tasks. Teachers can, thus, recognize the effect of the tasks on students' language production and on their language development.

\section{Classroom Discourse and Learners}

In second language teaching, it is important that learners should be introduced to various discourse patterns in different texts and interactions. 
In Libyan language classrooms, for example, the problem for learners is that they do not have much experience with a variety of interactive practices in the target language. They are likely to rely on the strategies acquired in their first language development, which may be inappropriate for the second language situation and may lead to miscommunication, perhaps, misunderstanding. McCarthy (1991, p.145) believes that naturalness is probably impossible in the classroom, but the feeling that being engaged in an authentic activity is important to the learner, as is the feeling that one is being taught authentic and naturally-occurring structures and vocabulary to use in simulations of real-life talk. Consequently, the teacher may try to explore natural language use in an authentic environment, so learners can get a better understanding of the discourse patterns associated with a given genre or speech event. For example, students can study speech acts in a service encounter, turntaking patterns in casual conversation between friends, opening and closing of answering machine messages, or other aspects of speech events. Learners can benefit from exploring the language and how it is used to achieve communicative goals in different contexts. This can help to create a second language learning environment that encourages them to reach a high level of competence and proficiency in the target language.

\section{Dimensions of Discourse}

As cited by Breen (2001), Fairclough (1989 \& 1992) provides a framework of discourse, which is made up of three components. These components are: a piece of text; an instance of discursive practice; and an instance of social practice. Applying this framework to the language 
classroom, the text of lessons is the available language or communicative data (spoken, written, or in other visual media such as pictures, diagrams or facial expressions). The discursive practices are how texts are produced and interpreted and how different types of texts are combined. The social practice refers to the organizational circumstances that generate and delimit both the specific text and discursive practices of lessons. In short, the interaction between the learner and the target language data is obviously situated within social action. In this regard, one should refer to what Breen (2001, p.316) points out that learners in discursive practices are obliged to participate overtly and covertly in the discourse of lessons. He presumes that learners should adopt a responsive role in relation to the teacher's management of the discourse and act individually in response to discursive pressure within teacher-learner interaction, tasks and activities during lessons. Furthermore, according to this author, they must navigate the discourse of the classroom and covertly exploit others' participation as opportunities to serve their own purposes. Besides, they need to define the situation on the basis of past experience and present understanding of the emerging culture of the classroom group and act in a way appropriate to that culture. Finally, learners have to participate with the teacher and other learners in the ongoing construction of lessons.

\section{Zpd and Scaffolding}

According to socio-cultural theory, (Vygotsky, 1978), the distance between what learners can do by themselves and what they can do with guidance from a teacher or a more capable peer creates a zone of proximal development within which interaction and discourse lead to the 
appropriation of new knowledge (pp.86-91). The theory holds that learners will use the techniques employed during collaborative efforts when encountering similar problems in the future. Thus learning takes place through collaborative problem-solving. Language learners may be unable to produce certain structures within a single utterance, but may build them up through interaction with the teacher or more skilful peer. Accordingly, the teacher can provide support to the learner to enable him/her to deal with the communicative tasks, which are beyond his/her linguistic capacity. It is through the collaborative problem-solving activity learners are provided with demonstrations, support, guidance, input and feedback. In these activities, the teacher withdraws slowly, letting the learner become more independent. Van Lier (2001, p.96) makes the condition that, for scaffolding to be of true pedagogical benefit, it must be temporary and the scaffold must be gradually dismantled as the learner shows signs of being capable of handling more of the task in question. Bruner (1983) calls this process "hand over", and he believes that without this gradual dismantling, scaffolding would simply produce dependence and helplessness.

Scaffolding can occur in either teacher-learner or learner-learner discourse. The teacher asks questions for elaborating and expanding and the students can scaffold one another in group work. The teacher invites and encourages students to participate in the discourse and the students choose the activity and their groups. Then the teacher comments on the students' performance by giving feedback to praise or to correct the wrong answers. Also, the students can be self-motivated and should be involved 
in this process that brings them to accept responsibility for their own learning by giving lots of initiatives.

In traditional teacher-learner discourse, we find that teachers depend on the initiation-response-evaluation pattern. The teacher initiates a question to check the student's knowledge, a student responds, and the student's response is evaluated with feedback from the teacher. Since teacher-learner discourse consists of IRF (i.e., initiation, response, feedback), the teacher's questions require the students merely to reproduce previously-learned items. Van Lier (2001, p. 95) demonstrates that the teacher does all the initiating and closing and the students' work is done exclusively in the response slot. Therefore, the IRF format discourages student initiation and student repair work. In addition, the student will neither have any chance to interact authentically, ask questions, nor disagree with any point. This prevents the student from doing turn-taking, topic development, and activity-structuring work.

Sinclair and Brazil (1982) as cited by Van Lier (2001, p.91) that, "students have only very restricted opportunities to participate in the language of the classroom". However, he explains that teachers sometimes fear that learners might infect each other with linguistic errors or create some form of interlingual pidgin when they are left to their own devices (p. 92).

Other researchers such as Little, Ridley and Ushioda (2002) think that the teacher must enable learners to control the discourse, even from the very early stages of learning, as in parent-child scaffolding (p. 20). According to Mercer (1995, p.34) a teacher may elicit information, but 
he/she will also confirm or reject what learners say, repeat, elaborate or reformulate what learners say, just as parents do with their children.

In learner-learner discourse, there will be an opportunity for collaborative learning and peer scaffolding which enables learners to negotiate solutions to problems. Learners can construct new knowledge through discussion and reflection. Scaffolding can be provided by more capable peers or peers of equal ability. But at first there would be probably a risk of dominance in scaffolding by the more skilled ones, where he/she may not leave enough space for the other peer to engage in the discourse. Donato (1994) believes that peer scaffolding among learners of the same level is mutually beneficial. He states that that learners can expand their own L2 knowledge and extend the linguistic development of their peers. He further adds that a collective acquisition of the second language will be a result of effective peer scaffolding.

\section{Collaboration}

The collaborative conversation theory applies to the study of conversation between experts and novices and between people with different perspectives or different communicative goals. Richards and Schmidt (2002, p.124, 86) define collaborative learning as an approach to teaching and learning in which classrooms are organized so that students work together in small co-operative teams. Such an approach increases students' learning since (a) it is less threatening for many students, (b) it increases the amount of student participation in the classroom, (c) it reduces the need for competitiveness, and (d) it reduces the teacher's dominance in the classroom. They add that a form of collaborative 
learning in which specific roles and responsibilities for group-based activities is known as cooperative learning. According to Lightbown and Spada (1999, p.34) cooperative learning activities are those in which students must work together in order to complete a task or solve a problem. These techniques have been found to increase the selfconfidence of students, including weaker ones, because every participant in a co-operative task has an important role to play.

\section{The Importance of Feedback}

In discourse analysis, sometimes called back channelling, feedback is given while someone is speaking: for example, comments such as "uh", "yeah", "really", "smiles", and shakes or nods of the head that indicate success or failure in communication. In the classroom, it is the teacher's comments on learners' performance or other information which learners receive concerning their success on learning tasks or tests, either from the teacher or other qualified peers. (Richards and Schmidt 2002, p.199)

Teachers can use feedback as an indirect error correction when they points out the problem and asks learners to correct it. Coulthard (1985, p.125) states: "it is essential for him [the teacher] to provide feedback to indicate whether a particular answer was the one he was looking for". In feedback, the teacher may rephrase an incorrect or incomplete learner utterance by changing one or more sentence components such as subject, verb, or object while still referring to its central meaning.

\section{The Task}

Learner Group: 
Intermediate adult learners of English

Task:

Giving the students something visual such as a map or diagram of a small town showing the main landmarks of the city such as the post office, bank, avenues, newsagent, grocers...etc.

The Goal:

Solve-problem or service encounter

The Lesson:

Learning how to use directions or planning doing shopping Pre-task:

The teacher gives some examples of how to direct people from one place to another. He may also give some key words to help the learner build up questions and answers.

Activity 1:

Forming pair groups; each learner chooses his/her pair. They take turns asking and answering questions. They might write down their dialogue, for example:

S1: Excuse me...could you please tell me where the post office is?

S2: Yes, of course...go straight ahead till you reach the roundabout... turn left... and you will find it on your left hand side

Principles Used: 
- The teacher scaffolds learners in case of a mistake. There could be peer scaffolding from more skilful peers.

- Learners choose their peer group with autonomy.

- Writing supporting speaking, when key words are given and learners write down their dialogue.

Learning Outcome:

- Learners use open questions.

- They use language naturally with authentic turn-taking.

- They navigate and initiate the discourse.

- The teacher withdraws when learners control the discourse.

Activity 2:

Learners reform into large groups to ask and answer different questions and change the role-play in the exercise.

Principles:

- They use interaction and practice that leads to authentic performance.

- The teacher monitors and gives support if required.

- If discourse breaks down, the teacher gives corrective feedback. Learning Outcome:

- Learners predict answers to questions. 
- They work collaboratively and produce new sentences in the target language.

Post Task:

The teacher comments on the discourse and revises the task by asking various questions to different learners and encourages them by emphasizing the good features of their work.

\section{CONCLUSION}

This paper has highlighted the importance of the effective classroom discourse in second/foreign language learning. Also it has showed the significance of the types of the interactions inside the class. It suggests that teachers should work on improving the communicative competence of their students instead of focusing only on their linguistic competence. Because learning can occur as the result of the interactions in the classroom, the role of the teacher is essential to facilitate learning. It is recommended that learners should be introduced to different kinds of discourse in the target language. Learners cannot perform the task on their own but they need the assistance of the teacher. Therefore, the teacher should try to explore natural language use in an authentic environment, and this can help in creating an encouraging second language learning environment. 


\section{REFERENCES}

Breen, M. (2001) 'Navigating the Discourse: on What is Learned in the Language Classroom', in C. Candlin and N. Mercer (eds.), 306-322

Bruner, J. (1983) Child's Talk: Language to Use Language. New York: Norton.

Coulthard, M. (1985) Introduction to Discourse Analysis. New York: Longman.

Donato, R. (1994). 'Collective Scaffolding in Second Language Learning'. In Lantof, J. P. \& Apple, G. (eds.). Vegotskian Approaches to Second Language Research. 3-65, Norwood, N. J. Ablex.

Fairclough, N. (1989) Language and Power. London: Longman.

Fairclough, N. (1992) Discourse and Social Change. Cambridge: Polity Press.

Lightbown, M. P. \& Spada, N. (1999) 'Factors affecting Second Language Learning'. In Candlin, C. \& Mercer, N. (eds.). Pp 28-43, English Language Teaching inits Social Context. London \& New York: Routledge.

Little, D., Ridley, J. and Ushioda, E.(2002). Towards Greater Learner Autonomy in the Foreign Language Classroom. Dublin: Authentic 
McCarthy, M. (1991). Discourse Analysis for Language Teachers. Cambridge: Cambridge University Press.

Mercer, N. (1995). The Guided Construction of Knowledge: Talk amongst Teachers and Learners. Clevedon: Multilingual Matters.

Mercer, N. (2000). Words and Minds: How We Use Language to Think Together.London and New York: Routledge.

Richards, C. J. \& Schmidt, R. (2002). Longman Dictionary of Language Teaching and Applied Linguistics. UK: Pearson Education Limited.

Sinclair, J. M. \& Brazil, D. (1982). Teacher Talk. Oxford: Oxford University Press.

Van Lier, L. (2001). 'Constraints and Resources in Classroom Talk: Issues of Equality and Symmetry'. In Canden, C. \& Mercer English Language Teaching in its Social Context. London \& New York.

Vygotsky, L. (1978). Mind in Society. Cambridge, MA: Harvard University Press. 